\title{
Assessment of farmers' knowledge and awareness regarding pest control technologies in the apple growing belts of Kashmir valley
}

\author{
Farheen Naqash and S. A. Wani
}

See end of the paper for authors' affiliations

Correspondence to :

Farheen Naqash

School of Agricultural

Economics and Horti-

Business Management,

Sher-e-Kashmir University

of Agricultural Sciences and

Technology of Kashmir,

Shalimar Campus,

Srinagar (J\&K) India

Email : naqashfarheen@ gmail.com
Paper History :

Received : 01.06.2019;

Revised :06.07.2019;

Accepted : 08.08.2019
ABSTRACT : A study on "assessment of farmers' knowledge and awareness regarding pest control technologies in the apple growing belts of Kashmir valley" was carried out in the three zones of the Kashmir valley during 2017-18. Apple being main horticultural crop has predominant position in area, production and productivity. Both primary and secondary data was analyzed to interpret the results for this study. The data was collected extensively from six blocks of the Kashmir Valley, two each from North, South and the Central zone by using multi-stage stratified sampling technique and the secondary data was also collected from various published/unpublished records. The study has pointed out to the need for a detailed look on the pesticide-use pattern, distribution systems, regulatory mechanism and farmers perception about pesticide use at a micro level. The results of the study revealed that expenditure incurred on pesticides is quite high in apple. Besides that, not only the intensity of pesticide use but also the high risk pesticides are being used in crop production in the study area. The study indicated that the farmers apply pesticides indiscriminately in violation of the scientific recommendations. About one-third of the pesticides available in the market are reported to be either sub-standard or spurious. The existence of unlicensed dealers/ traders has further accentuated the magnitude of malpractices in the pesticide delivery system. The results of the study further indicated that farmers had limited knowledge of pest management as well as the consequences of pesticide use. Almost all the apple-growing farmers $(95 \%)$ were of the opinion that there was heavy severity of disease in the study area. The expenditure on fertilizers and manures, average price of pesticide and pest intensity has significantly influenced the pesticide use in apple. High pesticide use was observed and most of the pesticides belong to high and moderate risk chemicals. The determinants of apple yield revealed that the estimated co-efficients for fertilizer expenditure, area under the crop and expenditure on pesticides were found to be positive and significant. Farmers are willing to pay average price premium upto 15 per cent for environmentally safer formulations of pesticides. This confirms that a market exists for safer or environment friendly pesticides in the study area. Increasing farmers' awareness of pesticide hazards, proper regulation of pesticides and promotion of spray schedule adoption is essential for reducing adverse economic and environmental implications. The study has put forth a few policy suggestions for encouraging scientific application of pesticides and reducing the negative externalities arising from pesticide-use.

KEY WORDS : Pesticides, Negative externalities, Spurious/sub-standard pesticides, Apple, Kashmir

HOW TO CITE THIS PAPER : Naqash, Farheen and Wani, S.A. (2019). Assessment of farmers' knowledge and awareness regarding pest control technologies in the apple growing belts of Kashmir valley. Internat. Res. J. Agric. Eco. \& Stat., 10 (2) : 221-233, DOI : 10.15740/HAS/IRJAES/10.2/221-233. Copyright@ 2019: Hind Agri-Horticultural Society. 